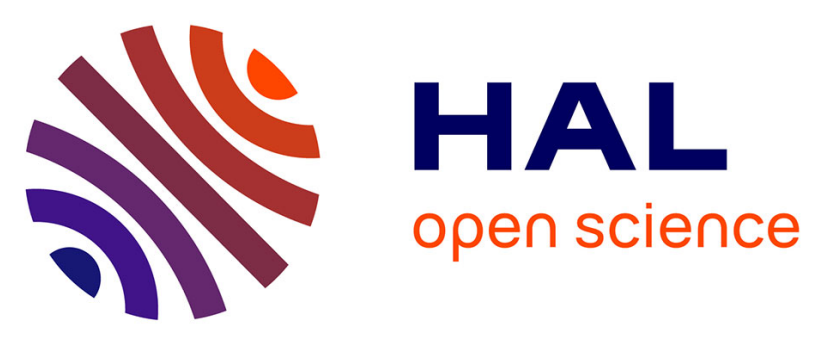

\title{
Algebraic nonlinear estimation and flatness-based lateral/longitudinal control for automotive vehicles
}

Lghani Menhour, Brigitte d'Andréa-Novel, Clément Boussard, Michel Fliess, Hugues Mounier

\section{- To cite this version:}

Lghani Menhour, Brigitte d'Andréa-Novel, Clément Boussard, Michel Fliess, Hugues Mounier. Algebraic nonlinear estimation and flatness-based lateral/longitudinal control for automotive vehicles. ITSC 2011 - 14th International IEEE Conference on Intelligent Transportation Systems, Oct 2011, Washington, United States. pp.CDROM. hal-00611950

\section{HAL Id: hal-00611950 \\ https://hal-polytechnique.archives-ouvertes.fr/hal-00611950}

Submitted on 27 Jul 2011

HAL is a multi-disciplinary open access archive for the deposit and dissemination of scientific research documents, whether they are published or not. The documents may come from teaching and research institutions in France or abroad, or from public or private research centers.
L'archive ouverte pluridisciplinaire HAL, est destinée au dépôt et à la diffusion de documents scientifiques de niveau recherche, publiés ou non, émanant des établissements d'enseignement et de recherche français ou étrangers, des laboratoires publics ou privés. 


\title{
Algebraic nonlinear estimation and flatness-based lateral/longitudinal control for automotive vehicles
}

\author{
Lghani Menhour, Brigitte d'Andréa-Novel, Clément Boussard, Michel Fliess and Hugues Mounier
}

\begin{abstract}
A combined longitudinal and lateral vehicle control is presented. It employs flatness-based control and new algebraic estimation techniques for the numerical differentiation of noisy signals. This nonlinear control is designed for automatic path-tracking via vehicle steering angle and driving/braking wheel torque. It combines the control of the lateral and longitudinal movements in order to ensure an accurate tracking of straight or curved trajectories. It can also be used to perform a combined lane-keeping and steering control during critical driving situations such as obstacle avoidance, stop-and-go control, lane-change maneuvers or any other maneuvers. Promising results have been obtained using the noisy experimental data acquired by a laboratory vehicle under high dynamic loads and characterized by high lateral accelerations.
\end{abstract}

\section{INTRODUCTION}

The research on intelligent transportation systems, the aim of which is to improve road safety, is getting more and more active. Some assistance systems have been developed in order to help the driver in critical situations, and to improve the vehicle stability and steerability. Among those, we can find for example Anti-Lock Braking System, Electronic Stability program, Adaptive Cruise Control and recently four wheel steering systems.

To develop autonomous vehicles, the design of combined lateral and longitudinal control is required to perform some coupled maneuvers as stop-and-go control with obstacle avoidance, lane-change maneuvers, and the appropriate steering angle to ensure lane keeping. A majority of the strategies proposed in the previous published works deal with longitudinal or lateral control separately, and rarely with a combined implementation, for example to perform a braking action in curve. In [22], a survey of driver models and their application in automotive dynamics is presented, and papers referred in this large inventory deal only with steering vehicle control. In [25] an integration of longitudinal and lateral control for

This work was supported by the French national project INOVE/ANR 2010 BLANC 308.

L. Menhour and B. d'Andréa-Novel are with Mines-ParisTech, CAOR-Centre de Robotique, Mathématiques et systèmes, 60 boulevard Saint-Michel, 75272 Paris cedex 06, France.

lghani.menhour@mines-paristech.fr

brigitte.dandrea-novel@mines-paristech. fr

Clément Boussard is with IMARA, INRIA, Domaine de Voluceau Rocquencourt, B.P. 105, 78153 Le Chesnay, France.

clement.boussardeinria.fr

Michel Fliess is with LIX (CNRS, UMR 7161) École polytechnique, 91128 Palaiseau, France.

Michel.Fliess@polytechnique.edu

Hugues Mounier is with L2S (UMR 8506), CNRS - Supélec - Université Paris-Sud, 3 rue Joliot-Curie, 91192 Gif-sur-Yvette, France.

hugues.mounier@lss.supelec.fr platooning in highways is presented in a decoupled way. The steering control strategy for the autonomous lane change in highway or for urban steering driving are also presented in several works, like [2], [4], [12], [13], [16].

Longitudinal control is considered in some papers, for example in [17], [20], [27], [28] with some stop-and-go control strategies to keep a safety distance and avoid collisions.

On the other hand, some works have dealt with the problem of comfort and improvements of a ground vehicle handling through the joint braking and suspension control, see for example [23]. In [24] this approach is extended by the introduction of the steering control in order to improve the vehicle stability, the longitudinal motion is not considered as a state component but as a variable parameter. ${ }^{1}$

In [19], [14], the authors propose an inventory concerning longitudinal and lateral control, and point out that in the literature the longitudinal control and the steering control are treated separately in most of the cases. However, in [3], [5], a nonlinear global chassis control law is proposed to follow desired trajectories in yaw rate and in longitudinal acceleration via braking torques only without active steering control.

The present paper deals with the problem of a nonlinear coupled longitudinal and lateral control based on algebraic nonlinear estimation techniques [7], [18] and differential flatness [8], [9] (see also [10] for a related approach). To deal with this method, a three degrees-of-freedom two wheels vehicle model is considered. The estimation approach allows to obtain a very good estimation of the derivatives of noisy signals. Indeed the sensors used in a real automotive application are generally low cost and their measurements are very noisy. Hence it is not easy to use these measurements directly to obtain the reference signals for the control applications. For this reason, algebraic estimation is useful.

The remainder of this paper is organized as follows. Section II presents the $3 \mathrm{DoF}$ two wheels vehicle model used for the control law design. Section III describes the design steps of a flatness-based robust combined longitudinal and lateral non linear control and algebraic nonlinear estimation. Section IV presents detailed experimental results using the noisy measurements acquired on real roads with high dynamic loads. Some concluding remarks and future work are presented in Section V.

${ }^{1}$ See also [30]. 


\section{VEHICLE MODELS AND COUPLED DYNAMIC ANALYSIS}

Two nonlinear vehicle models are used: the first one is a $3 \mathrm{DoF}$ two wheels nonlinear model (3DoF-NLTWVM) which will be used to design a combined nonlinear control law. The second is a $10 \mathrm{DoF}$ four wheels nonlinear model (10DoF-NLFWVM) which will be used as a complete vehicle simulator to test the proposed control law under high loads with curved trajectories. In the following subsections we present the reasons for which the coupled nonlinear vehicle models are used.

\section{A. Coupled dynamics}

The aim of designing a combined lateral and longitudinal controller is to enhance and ensure a certain level of control performance, and realize some combined maneuvers. Therefore, to ensure a combined robust control, coupled vehicle dynamics must be taken into account. Clearly, to satisfy these requirements, the identification of some coupling effects is an important step to design a combined control law:

- The first coupling that can be cited is the one related to the kinetics vehicle. The longitudinal motion is affected by the steering angle; in fact when the vehicle wheels are steered, the longitudinal forces are functions of the wheel forces and steering angle. The lateral deviation is also a function of the longitudinal speed and yaw angle. The same reasoning is done for the lateral forces and the longitudinal displacement.

- The load transfer is an important coupling of the vehicle dynamics. This coupling is the consequence of the braking/traction (change the weight distribution between the front and rear tires), lateral acceleration (change the weight distribution between the right and left tires), road bank angle, road slope angle, roll and suspension motions. All these coupling are considered in the computation of the tire vertical forces.

- Another coupling effect comes from the behavior of the tires; this coupling is expressed by the longitudinal and lateral forces. In fact, to obtain a realistic representation of the vehicle behaviors in extreme driving situations, the coupling of longitudinal and lateral forces is required. To achieve this goal, the coupled formula of Pacejka [21] model is used. In this model the coupling of longitudinal slip, lateral slip, vertical forces and camber angle is taken into account.

\section{B. 3DoF Nonlinear Two Wheels Vehicle Control Model}

The 3DoF-NLTWVM shown in Figure 1 used to design the combined control law provides a sufficient approximation of the longitudinal and lateral dynamics of the vehicle in normal driving situations. This model is composed from the longitudinal $V_{x}$, lateral $V_{y}$ and yaw $\dot{\psi}$ motions (see table I for notations).

The coupled equations of this model are:

$$
\left\{\begin{array}{l}
m a_{x}=m\left(\dot{V}_{x}-\dot{\psi} V_{y}\right)=\left(F_{x 1}+F_{x 2}\right) \\
m a_{y}=m\left(\dot{V}_{y}+\dot{\psi} V_{x}\right)=\left(F_{y 1}+F_{y 2}\right) \\
I_{z} \ddot{\psi}=M_{z 1}+M_{z 2}
\end{array}\right.
$$

TABLE I

SOME NOTATIONS

\begin{tabular}{|c|c|}
\hline Symbol & Variable name \\
\hline$V_{x}$ & longitudinal speed $[\mathrm{km} \cdot \mathrm{h}]$ \\
\hline$V_{y}$ & lateral speed $[\mathrm{km} . \mathrm{h}]$ \\
\hline$a_{x}$ & longitudinal acceleration $\left[\mathrm{m} / \mathrm{s}^{2}\right]$ \\
\hline$a_{y}$ & lateral acceleration $\left[\mathrm{m} / \mathrm{s}^{2}\right]$ \\
\hline$\dot{\psi}$ & yaw rate $[\mathrm{rad} / \mathrm{s}]$ \\
\hline$\psi$ & yaw angle $[\mathrm{rad}]$ \\
\hline$\beta$ & sideslip angle $[\mathrm{rad}]$ \\
\hline$\omega_{i}$ & wheel angular speed of the wheel $i[\mathrm{rad} / \mathrm{s}]$ \\
\hline$T_{\omega}$ & wheel torque $[\mathrm{Nm}]$ \\
\hline$T_{m}$ & wheel traction torque $[\mathrm{Nm}]$ \\
\hline$T_{b}$ & wheel braking torque $[\mathrm{Nm}]$ \\
\hline$T_{b f}$ & front wheel braking torque $[\mathrm{Nm}]$ \\
\hline$T_{b r}$ & rear wheel braking torques $[\mathrm{Nm}]$ \\
\hline$\delta$ & wheel steer angle $[\mathrm{deg}]$ \\
\hline$C_{f}, C_{r}$ & front and rear cornering stiffnesses $\left[N . \mathrm{rad}^{-1}\right]$ \\
\hline$F_{x i}$ & longitudinal force in the vehicle coordinate $[N]$ \\
\hline$F_{y i}$ & lateral force in the vehicle coordinate $[N]$ \\
\hline$F_{x f}$ & front longitudinal force in the wheel coordinate $[N]$ \\
\hline$F_{y f}$ & front lateral force in the wheel coordinate $[N]$ \\
\hline$R$ & tire radius $[m]$ \\
\hline$R_{r}$ & road radius $[m]$ \\
\hline $\begin{array}{l}L_{f}, L_{r} \\
I_{z}\end{array}$ & $\begin{array}{l}\text { distances from the CoG to the front and rear axles }[\mathrm{m}] \\
\text { yaw moment of inertia }\left[\mathrm{Kg}^{\left.-\mathrm{m}^{-2}\right]}\right.\end{array}$ \\
\hline $\begin{array}{l}I_{z} \\
I_{r}\end{array}$ & wheel moment of inertia $\left[\mathrm{kgm}^{2}\right]$ \\
\hline$\alpha_{i}$ & tire slip angle $[\mathrm{rad}]$ \\
\hline$g$ & acceleration due to gravity $\left[\mathrm{m} / \mathrm{s}^{2}\right]$ \\
\hline$m$ & vehicle mass $\left[\mathrm{kgm}^{2}\right]$ \\
\hline$M_{z}$ & yaw moment $[\mathrm{Nm}]$ \\
\hline
\end{tabular}

The forces and moments of Eq. (1) in the vehicle coordinates taking into account the kinetics coupling are:

$$
\left\{\begin{array}{l}
F_{x 1}=F_{x f} \cos (\delta)-F_{y f} \sin (\delta) \\
F_{x 2}=F_{x r} \\
F_{y 1}=F_{x f} \sin (\delta)+F_{y f} \cos (\delta) \\
F_{y 2}=F_{y r} \\
M_{z 1}=L_{f}\left(F_{y f} \cos (\delta)+F_{x f} \sin (\delta)\right) \\
M_{z 2}=-L_{r} F_{y r}
\end{array}\right.
$$

Considering the small angles assumption, the forces and moments, in Eq. (2) become as follows:

$$
\left\{\begin{array}{l}
F_{x 1}=F_{x f}-F_{y f} \delta \\
F_{x 2}=F_{x r} \\
F_{y 1}=F_{x f} \delta+F_{y f} \\
F_{y 2}=F_{y r} \\
M_{z 1}=L_{f}\left(F_{y f}+F_{x f} \delta\right) \\
M_{z 2}=-L_{r} F_{y r}
\end{array}\right.
$$

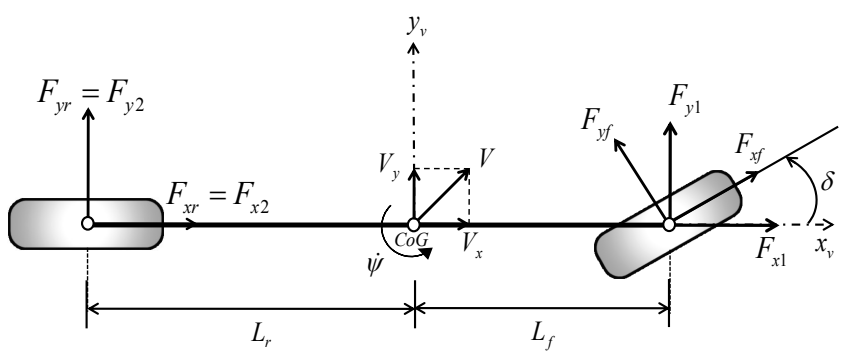

Fig. 1. Nonlinear two wheeled vehicle model 
In Eq. (1) the longitudinal forces are calculated using the dynamical model of the wheels. For the front wheel:

$$
F_{x f}=(1 / R)\left(-I_{r} \dot{\omega}_{f}+T_{m}-T_{b f}\right)
$$

Considering that the vehicle is only propelled by the front wheel, the dynamical model of the rear wheel is as follows:

$$
F_{x r}=-(1 / R)\left(T_{b r}+I_{r} \dot{\omega}_{r}\right)
$$

The wheels rotations $\omega_{f}$ and $\omega_{r}$ are supposed to be measured through odometers. They are introduced as external inputs in the equations of the 3DoF-NLTWVM. We assume that the rear braking torque $T_{b r}$ is equal to the front one $T_{b f}$. The wheels rotation accelerations will be estimated using the algebraic nonlinear estimation and the measured rotation speeds which are available on the vehicle's CAN bus. Note that the lateral tire forces, we have, modeled as proportional to the slip angles of each axle. The front and rear forces $\left(F_{y f}=C_{f} \alpha_{f}, F_{y r}=C_{r} \alpha_{r}\right)$ are defined as follows:

$$
\left\{\begin{array}{l}
F_{y f}=C_{f}\left(\delta-\frac{V_{y}+\dot{\psi} L_{f}}{V_{x}}\right) \\
F_{y r}=-C_{r}\left(\frac{V_{y}-\dot{\psi} L_{r}}{V_{x}}\right)
\end{array}\right.
$$

where $C_{f}$ and $C_{r}$ are the cornering stiffness for the front and rear tires respectively. The longitudinal speed is considered different from zero $\left(V_{x}>\varepsilon\right)$. Replacing Eq. (3), (4), (5) and (6) in Eq. (1) yields:

$$
\left\{\begin{array}{l}
m \dot{V}_{x}=m \dot{\psi} V_{y}-\frac{I_{r}}{R}\left(\dot{\omega}_{r}+\dot{\omega}_{f}\right)+\frac{1}{R}\left(T_{m}-T_{b f}-T_{b r}\right) \\
+C_{f}\left(\frac{V_{y}+L_{f} \dot{\psi}}{V_{x}}\right) \delta-C_{f} \delta^{2} \\
m \dot{V}_{y}=-m \dot{\psi} V_{x}-C_{f}\left(\frac{V_{y}+L_{f} \dot{\psi}}{V_{x}}\right)-C_{r}\left(\frac{V_{y}-\dot{\psi} L_{r}}{V_{x}}\right) \\
+(1 / R)\left(T_{m}-T_{b f}\right) \delta+\left(C_{f}-\frac{I_{r}}{R} \dot{\omega}_{f}\right) \delta \\
I_{z} \ddot{\psi}=-L_{f} C_{f}\left(\frac{V_{y}+L_{f} \dot{\psi}}{V_{x}}\right)+L_{r} C_{r}\left(\frac{V_{y}-L_{r} \dot{\psi}}{V_{x}}\right) \\
+\left(L_{f} / R\right)\left(T_{m}-T_{b f}\right) \delta+L_{f}\left(T_{m}-\frac{I_{r}}{R} \dot{\omega}_{f}\right) \delta
\end{array}\right.
$$

The longitudinal movement is controlled via the traction/braking wheel torque $T_{\omega}=T_{m}-T_{b}$ with $T_{b}=T_{b f}+T_{b r}$, and the lateral movement via the steering angle $\delta$. Define the two control variables:

$$
\left\{\begin{array}{l}
u_{1}=T_{\omega} \\
u_{2}=\delta
\end{array}\right.
$$

The model given by Eq. (7) may now be written as follows:

$$
\dot{x}=f(x, t)+g(x) u+g_{1} u_{1} u_{2}+g_{2} u_{2}^{2}
$$

where

$$
f(x, t)=\left[\begin{array}{c}
\dot{\psi} V_{y}-\frac{I_{r}}{m R}\left(\dot{\omega}_{r}+\dot{\omega}_{f}\right) \\
-\dot{\psi} V_{x}+\frac{1}{m}\left(-C_{f}\left(\frac{V_{y}+L_{f} \dot{\psi}}{V_{x}}\right)-C_{r}\left(\frac{V_{y}-L_{r} \dot{\psi}}{V_{x}}\right)\right) \\
\frac{1}{I_{z}}\left(-L_{f} C_{f}\left(\frac{V_{y}+L_{f} \dot{\psi}}{V_{x}}\right)+L_{r} C_{r}\left(\frac{V_{y}-L_{r} \dot{\psi}}{V_{x}}\right)\right)
\end{array}\right],
$$

$$
\begin{gathered}
g(x, t)=\left[\begin{array}{cc}
\frac{1}{m R} & \frac{C_{f}}{m}\left(\frac{V_{y}+L_{f} \dot{\psi}}{V_{x}}\right) \\
0 & \left(C_{f} R-I_{r} \dot{\omega}_{f}\right) / m R \\
0 & \left(L_{f} C_{f} R-L_{f} I_{r} \dot{\omega}_{f}\right) / I_{z} R
\end{array}\right], g_{1}=\left[\begin{array}{c}
0 \\
\frac{1}{m R} \\
\frac{L_{f}}{I_{z} R}
\end{array}\right], \\
g_{2}=\left[\begin{array}{c}
\frac{-C_{f}}{m} \\
0 \\
0
\end{array}\right]^{T}, x=\left[\begin{array}{c}
V_{x} \\
V_{y} \\
\dot{\psi}
\end{array}\right]^{T}, u=\left[\begin{array}{c}
u_{1} \\
u_{2}
\end{array}\right]^{T}
\end{gathered}
$$

\section{FLATNESS-BASED CONTROL}

In order to reduce the complexity of the nonlinear model in Eq. (8), nonlinear terms such as $u_{1} u_{2}$ and $u_{2}^{2}$ are neglected. ${ }^{2}$ Despite these simplifications some coupled behaviors are kept as shown by the functions $f(x, t)$ and $g(x, t)$. Eq. (8) becomes:

$$
\dot{x}=f(x, t)+g(x, t) u
$$

\section{A. Flatness property}

Consider the system

$$
\dot{x}=f(x, u)
$$

where $x=\left(x, \cdots, x_{n}\right) \in \mathbb{R}^{n}$ and $u=\left(u, \cdots, u_{m}\right) \in \mathbb{R}^{m}$. It is said to be differentially flat (see [8], [9] and [15], [26]) if, and only if,

- there exists a vector-valued function $h$ such that

$$
y=h\left(x, u, \dot{u}, \cdots, u^{(r)}\right)
$$

where $y=\left(y, \cdots, y_{m}\right) \in \mathbb{R}^{m}, r \in \mathbb{N}$;

- the components of $x=\left(x, \cdots, x_{n}\right)$ and $u=\left(u, \cdots, u_{m}\right)$ may be expressed as

$$
\begin{aligned}
& x=A\left(y, \dot{y}, \cdots, y^{\left(r_{x}\right)}\right), r_{x} \in \mathbb{N} \\
& u=B\left(y, \dot{y}, \cdots, y^{\left(r_{u}\right)}\right), r_{u} \in \mathbb{N}
\end{aligned}
$$

Remember that $y$ in Eq. (10) is called a flat output.

\section{B. Flatness-based longitudinal and lateral control}

1) A proof of flatness: We want to show that $y_{1}$ and $y_{2}$ given by

$$
\left\{\begin{array}{l}
y_{1}=V_{x} \\
y_{2}=L_{f} m V_{y}-I_{z} \dot{\psi}
\end{array}\right.
$$

define a flat output. Some algebraic manipulations yield

$$
\left[\begin{array}{c}
x=\left[\begin{array}{ccc}
V_{x} & V_{y} & \dot{\psi}
\end{array}\right]^{T}=A\left(y_{1}, y_{2}, \dot{y}_{2}\right)= \\
\frac{y_{2}}{L_{f} m}-\left(\frac{I_{z}}{L_{f} m}\right)\left(\frac{L_{f} m y_{1} \dot{y}_{2}+C_{r}\left(L_{f}+L_{r}\right) y_{2}}{C_{r}\left(L_{f}+L_{r}\right)\left(I_{z}-L_{r} L_{f} m\right)+\left(L_{f} m y_{1}\right)^{2}}\right) \\
-\left(\frac{L_{f} m y_{1} \dot{y}_{2}+C_{r}\left(L_{f}+L_{r}\right) y_{2}}{C_{r}\left(L_{f}+L_{r}\right)\left(I_{z}-L_{r} L_{f} m\right)+\left(L_{f} m y_{1}\right)^{2}}\right)
\end{array}\right]
$$

\footnotetext{
${ }^{2}$ The results of Section IV fully justify those approximations.
} 
and

$$
\begin{gathered}
{\left[\begin{array}{l}
\dot{y}_{1} \\
\ddot{y}_{2}
\end{array}\right]=\Delta\left(y_{1}, y_{2}, \dot{y}_{2}\right)\left(\begin{array}{l}
u_{1} \\
u_{2}
\end{array}\right)+\Phi\left(y_{1}, y_{2}, \dot{y}_{2}\right)} \\
\Rightarrow\left[\begin{array}{l}
u_{1} \\
u_{2}
\end{array}\right]=\Delta^{-1}\left(y_{1}, y_{2}, \dot{y}_{2}\right)\left(\left[\begin{array}{l}
\dot{y}_{1} \\
\ddot{y}_{2}
\end{array}\right]-\Phi\left(y_{1}, y_{2}, \dot{y}_{2}\right)\right)
\end{gathered}
$$

where

$$
\begin{gathered}
\Delta_{11}\left(y_{1}, y_{2}, \dot{y}_{2}\right)=\frac{1}{m R} \\
\Delta_{12}\left(y_{1}, y_{2}, \dot{y}_{2}\right)=\frac{C_{f}}{m}\left(\frac{V_{y}+L_{f} \dot{\psi}}{y_{1}}\right) \\
\Delta_{22}\left(y_{1}, y_{2}, \dot{y}_{2}\right)=+\left(-L_{f} m y_{1}+\frac{L_{r} C_{r}\left(L_{f}+L_{r}\right)}{y_{1}}\right) \frac{\left(L_{f} C_{f} R-L_{f} I_{\omega} \dot{\omega}_{f}\right)}{I_{z} R} \\
+\frac{\left(C_{r}\left(L_{f}+L_{r}\right)\left(V_{y}-L_{r} \dot{\psi}\right)-L_{f} m \dot{\psi} y_{1}^{2}\right)}{y_{1}^{2}} \frac{C_{f}\left(V_{y}+L_{f} \dot{\psi}\right)}{m y_{1}}-\frac{C_{r}\left(L_{f}+L_{r}\right)}{y_{1}} \frac{R C_{f}-I_{\omega} \dot{\omega}_{f}}{m R} \\
\Delta_{21}\left(y_{1}, y_{2}, \dot{y}_{2}\right)=\frac{\left(C_{r}\left(L_{f}+L_{r}\right)\left(V_{y}-L_{r} \dot{\psi}\right)-L_{f} m \dot{\psi} y_{1}^{2}\right)}{m R y_{1}^{2}} \\
\Phi_{2}\left(y_{1}, y_{2}, \dot{y}_{2}\right)=\dot{\psi} V_{y}-\frac{I_{\omega}}{m R}\left(\dot{\omega}_{r}+\dot{\omega}_{f}\right) \\
+\frac{C_{r}\left(L_{f}+L_{r}\right)\left(V_{y}-L_{r} \dot{\psi}\right)-L_{f} m \dot{\psi} y_{1}^{2}}{y_{1}^{2}} f_{1}(x, t)+\frac{L_{r} C_{r}\left(L_{f}+L_{r}\right)}{y_{1}} f_{3}(x, t)
\end{gathered}
$$

The flatness property holds therefore if the matrix $\Delta\left(y_{1}, y_{2}, \dot{y}_{2}\right)$ is invertible. It reads

$$
\begin{gathered}
\operatorname{det}\left(\Delta\left(y_{1}, y_{2}, \dot{y}_{2}\right)\right)=\Delta_{11} \Delta_{22}-\Delta_{21} \Delta_{12}= \\
\frac{\left(I_{\omega} \dot{\omega}_{f}-C_{f} R\right)\left(L_{f}^{2} y_{1}^{2} m^{2}-C r\left(L_{f}+L_{r}\right) L_{r} L_{f} m+C_{r} I_{z} L\right)}{I_{z} R^{2} y_{1} m^{2}} \neq 0
\end{gathered}
$$

This determinant, which depends only on the longitudinal speed $y_{1}=V_{x}$, is indeed nonzero:

- The wheel rotation acceleration is less than $R C_{f} / I_{\omega}$ : $R C_{f} / I_{\omega}$ is around $10^{4}$, then $I_{\omega} \dot{\omega}_{f}-C_{f} R \neq 0$.

- Notice that $I_{z}>L_{f} m$, then: $C_{r}\left(L_{r}+L_{f}\right)\left(I_{z}-L_{f} m\right)+$ $L_{f}^{2} m^{2} y_{1}^{2} \neq 0$.

Thus

$$
\begin{gathered}
u=\left[\begin{array}{c}
T_{\omega} \\
\delta
\end{array}\right]=B\left(y_{1}, \dot{y}_{1}, y_{2}, \dot{y}_{2}, \ddot{y}_{2}\right)= \\
\Delta^{-1}\left(y_{1}, y_{2}, \dot{y}_{2}\right)\left(\left[\begin{array}{l}
\dot{y}_{1} \\
\ddot{y}_{2}
\end{array}\right]-\Phi\left(y_{1}, y_{2}, \dot{y}_{2}\right)\right)
\end{gathered}
$$

with $r_{x}=1$ and $r_{u}=2$.

2) A tracking feedback control: In order to track the desired output trajectories $y_{1}^{r e f}$ and $y_{2}^{r e f}$, set

$$
\left[\begin{array}{c}
\dot{y}_{1} \\
\ddot{y}_{2}
\end{array}\right]=\left[\begin{array}{c}
\dot{y}_{1}^{r e f}+K_{1}^{1} e_{y_{1}}+K_{1}^{2} \int e_{y_{1}} d t \\
\ddot{y}_{2}^{r e f}+K_{2}^{1} \dot{e}_{y_{2}}+K_{2}^{2} e_{y_{2}}+K_{2}^{3} \int e_{y_{2}} d t
\end{array}\right]
$$

where, $e_{y_{1}}=y_{1}^{r e f}-y_{1}=V_{x}^{r e f}-V_{x}$ and $e_{y_{2}}=y_{2}^{r e f}-y_{2}$. The choice of the gain parameters $K_{1}^{1}, K_{1}^{2}, K_{2}^{1}, K_{2}^{2}$ and $K_{2}^{3}$ is straightforward.

\section{Algebraic nonlinear estimation}

It should be pointed out that the control law contains derivatives of reference signals which are estimated from measurements such as $V_{x}^{r e f}, V_{y}^{r e f}, \dot{\psi}^{r e f}$ and the derivatives of the measured front and rear rotation speed wheels $\omega_{f}$ and $\omega_{r}$. In order to perform this task and avoid the effects of the noisy measurements we propose to use the numerical differentiation based on an algebraic nonlinear estimation. ${ }^{3}$

This estimation is performed using the recent advances in [7], [18], which yield efficient real-time filters. The following formulae (see, e.g., [11]) may be used:

- Denoising:

$$
\hat{y}(t)=\frac{2 !}{T^{2}} \int_{t-T}^{t}(3(t-\tau)-T) y(\tau) d \tau
$$

- Numerical differentiation of a noisy signal:

$$
\dot{\hat{y}}(t)=-\frac{3 !}{T^{3}} \int_{t-T}^{t}(2 T(t-\tau)-T) y(\tau) d \tau
$$

Note that the sliding time window $[t-T, t]$ may be quite short.

Remark 3.1: The above estimation methods are not of asymptotic type and do not require any statistical knowledge of the corrupting noises (see [6] for details).

\section{COMPARISON WITH EXPERIMENTAL TESTS}

Several trials in presence of coupled traction/braking and steering maneuvers have been realized under high dynamic loads using the laboratory vehicle. During these tests a large set of dynamic parameters has been acquired such as longitudinal and lateral speeds, lateral and longitudinal accelerations, yaw rate, wheel rotation speeds, all forces and moments on four wheels, steering angle, etc. For these tests the acquisition device operates at frequency $400 \mathrm{~Hz}$.

These data have been used in our simulation process as reference trajectories, and compared to the obtained simulation results in closed loop with the experimental ones. More precisely, the combined control approach presented here is tested using several trials data performed on real race track as shown by curvature of Figure 4 . This section presents a test conducted on a race track which is performed under high dynamic loads as shown in Figures 2, 3, 4 and 5 which summarize some dynamic parameters of longitudinal and lateral motions. This test presents a coupled steering, accelerating, a sudden and sharp braking maneuver.

Figures 2 and 3 show the dynamic parameters of the two controlled vehicle models (3DoF-NLTWVM and 10DoFNLFWVM) which are close to those measured such as yaw rate, longitudinal speed, longitudinal and lateral accelerations. Notice also that the steering angle and braking/traction wheel torque provided by the combined control law are similar to the measured ones, this, for any given vehicle model (3DoF or 10DoF) and the performed maneuvers as illustrated in Figures 2 and 3 between the positions from $600 \mathrm{~m}$ to $750 \mathrm{~m}$ and from $1000 \mathrm{~m}$ to $1080 \mathrm{~m}$.

\footnotetext{
${ }^{3}$ See [1], [28], [29] for previous successful applications to intelligent transportation systems.
} 
During these two phases as mentioned on Figures 2 and 3, the combined steering and braking maneuvers are performed simultaneously in the most dangerous bends as illustrated in Figure 4. The performances of the control law in terms of tracking trajectories errors are depicted in Figure 5. Let us emphasize that these errors are quite small and satisfactory whatever the vehicle model used, the nature of the trajectory and the dynamic loads (lateral acceleration $-5 \mathrm{~m} / \mathrm{s}^{2} \leqslant a_{y} \leqslant$ $5 \mathrm{~m} / \mathrm{s}^{2}$ ).

During this test, the control law is efficient in simulation which is emphasized by the behavior of the controlled models being close to the measured one. This remark is verified especially when the $10 \mathrm{DoF}$ vehicle model is coupled with the nonlinear flat control law, indeed, as shown by Figure 4, the curvature of 3DoF-NLTWVM + nonlinear flat control is slightly different from the reference road curvature.
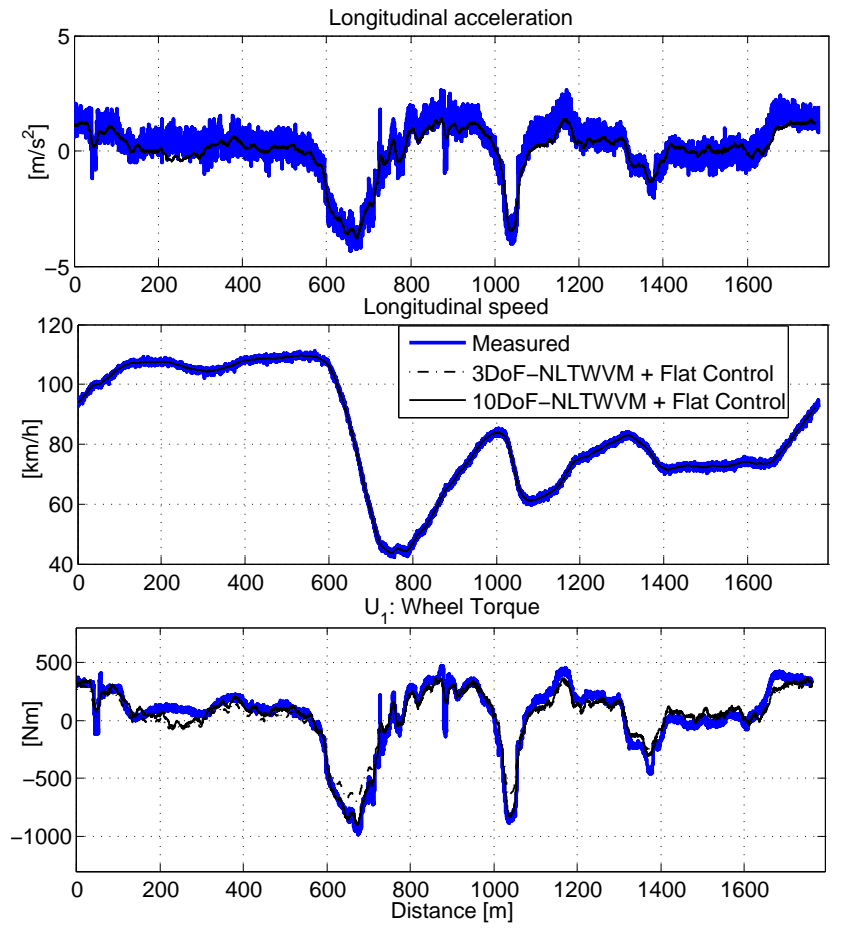

Fig. 2. Results of longitudinal behaviors: longitudinal acceleration, longitudinal speed and traction/braking torque control

From the results obtained with the two tests, the control law provided more realistic behaviors in terms of the tracking trajectories, when coupling the braking/traction torque and steering angle on a realistic simulator 10DoF-NLFWVM. This shows the effectiveness and the ability of the combined control law to operate under extreme and coupled nonlinear vehicle behaviors (for lateral acceleration $-5 \mathrm{~m} / \mathrm{s}^{2} \leqslant$ $a_{y} \leqslant 5 \mathrm{~m} / \mathrm{s}^{2}$ and longitudinal acceleration $-5 \mathrm{~m} / \mathrm{s}^{2} \leqslant a_{x} \leqslant$ $\left.3.5 \mathrm{~m} / \mathrm{s}^{2}\right)$ in curved trajectories $(20 \mathrm{~m}<R<35 \mathrm{~m})$. It should be pointed out that the emergency situations, such as collisions and obstacle avoidance, lane-change maneuvers, can easily cause critical dynamical driving situations. For this reason the performance of the control law must be tested under high dynamics loads.
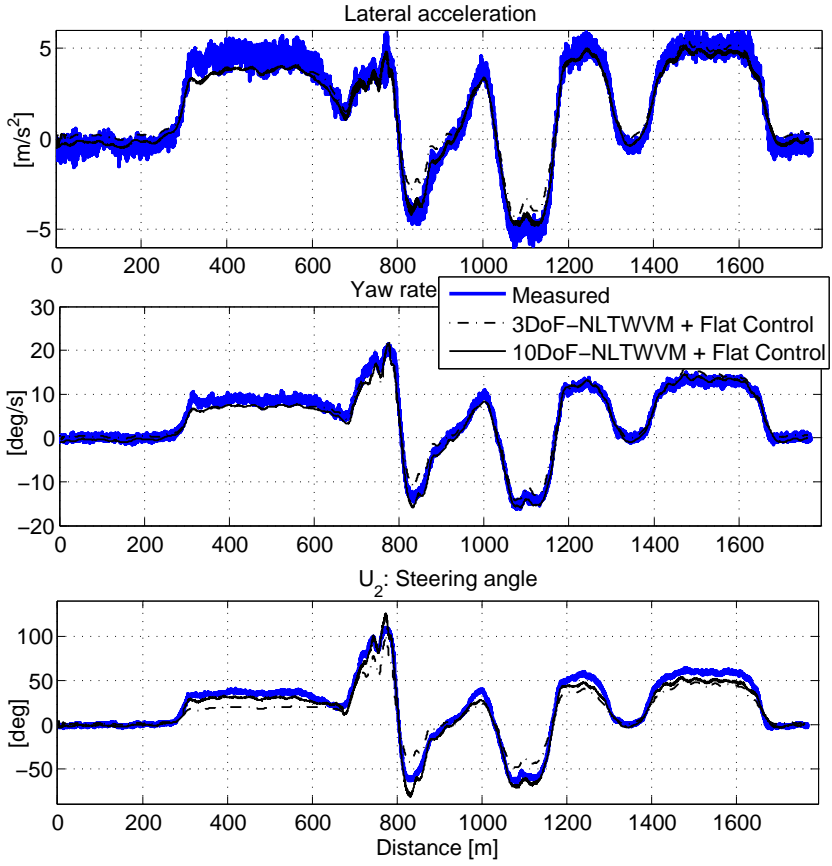

Fig. 3. Results of lateral behaviors: lateral acceleration, yaw rate and steering angle control

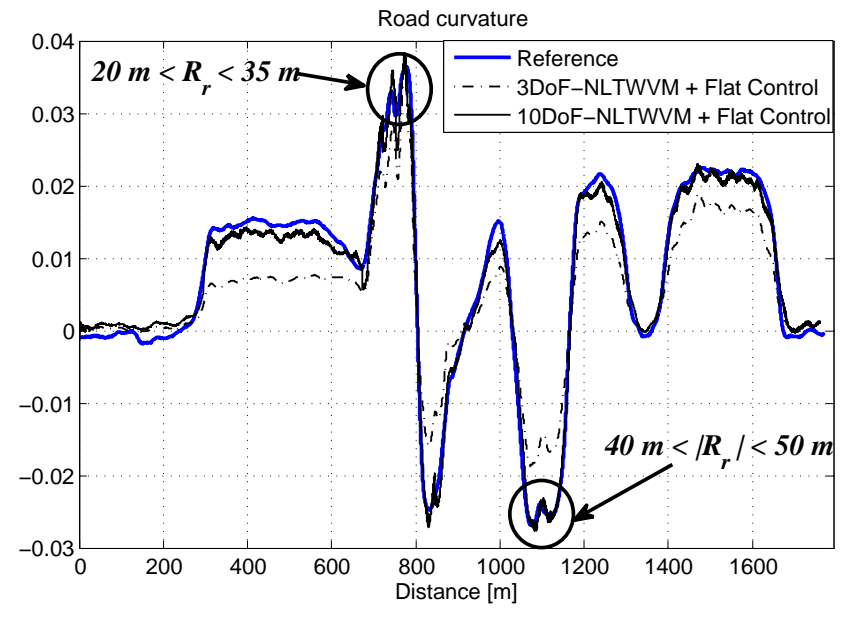

Fig. 4. Curvatures: reference and controlled vehicle model curvatures

Remark 4.1: Let us emphasize that our first results show that the performance of the control law is not affected by the model simplifications (nonlinear terms in the control inputs). 

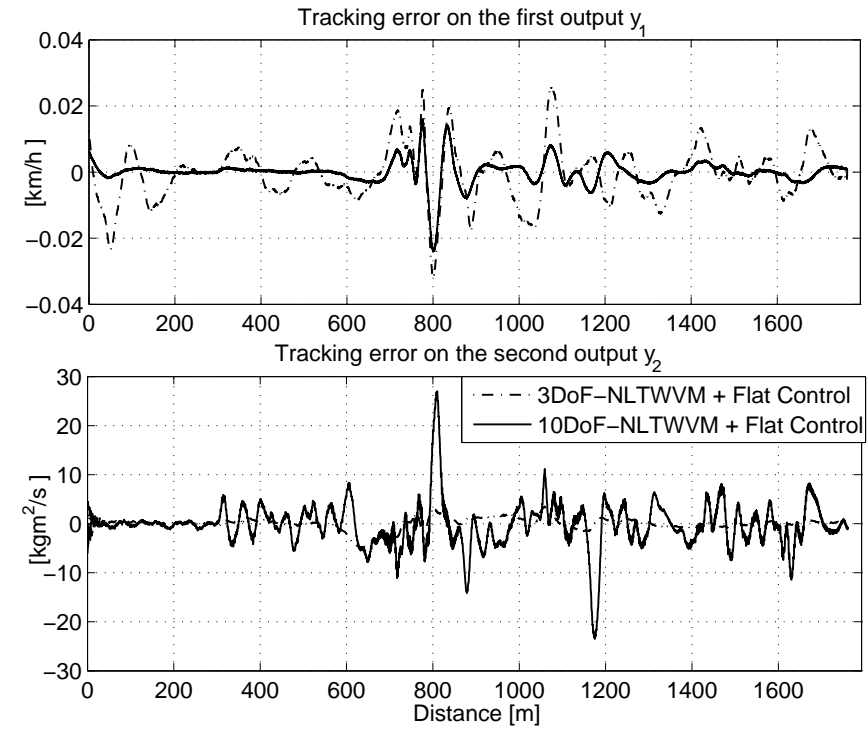

Fig. 5. Tracking errors on first and second outputs

\section{CONCLUSIONS AND FUTURE WORK}

The comparison with experimental results shows that the proposed control law is able to track a coupled longitudinal and lateral desired dynamics even under high dynamics loads and sudden and sharp maneuvers.

Future works will be devoted to the study of some combined tasks, like obstacle avoidance or lane change maneuvers during stop-and-go control to maintain a constant spacing between the cars using the inter-distance model [17].

\section{REFERENCES}

[1] H. Abouaïssa, M. Fliess, V. Iordanova, C. Join, "Vers une caractérisation non linéaire d'un réseau autoroutier", $3^{e s} J$. Identif. Modélisation Expérimentale, Douai, 2011.

(http://hal.archives-ouvertes.fr/hal-00572818/en/)

[2] J. Ackermann, J. Guldner, W. Sienel, R. Steinhauser, V. I. Utkin, "Linear and nonlinear controller design for robust automatic steering", IEEE Trans. Control Syst. Techno., vol. 3, 1995, pp. 112-143.

[3] B. d'Andréa-Novel, M. Ellouze, "Tracking with stability for a vehicle braking in a corner", $40^{\text {th }}$ IEEE Conf. Decision Control, Orlando, 2001.

[4] V. Cerone, M. Milanese, D. Regruto, "Combined automatic lanekeeping and driver's steering through a 2-DOF control strategy", IEEE Trans. Control Syst. Techno., vol. 17, 2009, pp. 135-142.

[5] H. Chou, B. d'Andréa-Novel, "Global vehicle control using differential braking torques and active suspension forces", Vehicle Syst. Dynamics, vol. 43, 2005, pp. 261-284.

[6] M. Fliess, "Analyse non standard du bruit", C.R. Acad. Sci. Paris, vol. I-342, 2006, pp. 797-802.

[7] M. Fliess, C. Join, H. Sira-Ramírez, "Non-linear estimation is easy", Int. J. Model. Identif. Control, vol. 4, 2008, pp. 12-27. (http://hal.archives-ouvertes.fr/inria-00158855/en/)

[8] M. Fliess, J. Lévine, P. Martin, P. Rouchon, "Flatness and defect of nonlinear systems: introductory theory and examples", Int. J. Control, vol. 61, 1995, pp. 1327-1361.

[9] M. Fliess, J. Lévine, P. Martin, P. Rouchon, "A Lie-Bäcklund approach to equivalence and flatness of nonlinear systems", IEEE Trans. Automat. Control, vol. 44, 1999, pp. 922-937.

[10] S. Fuchshumer, K. Schlacher, T. Rittenschober, "Nonlinear vehicle dynamics control - A flatness based approach", $44^{\text {th }}$ IEEE Conf. Decision Control \& Europ. Control Conf., Seville, 2005.
[11] F.A. García Collado, B. d'Andréa-Novel, M. Fliess, H. Mounier, "Analyse fréquentielle des dérivateurs algébriques", XXII ${ }^{e}$ Coll. GRETSI, Dijon, 2009.

(http://hal.archives-ouvertes.fr/inria-00394972/en/)

[12] J. Guldner, W. Sienel, H.-S. Tan, J. Ackermann, S. Patwardhan, T. Bunte, "Robust automatic steering control for look-down reference systems with front and rear sensors", IEEE Trans. Control Syst. Techno., vol. 7, 1999, pp. 2-11.

[13] C. Hatipoglu, Ü. Özgüner, K.A. Redmill, "Automated Lane Change Controller Design", IEEE Trans. Intel. Transport. Syst., vol. 4, 2003 , pp. 13-22.

[14] A. Khodayari, A. Ghaffari, S. Ameli, J. Flahatgar, "A historical review on lateral and longitudinal control of autonomous vehicle motions", IEEE Int. Conf. Mechanical Electrical Techno., Singapore, 2010.

[15] J. Lévine, Analysis and Control of Nonlinear Systems - A Flatnessbased Approach, Springer, 2009.

[16] R. Marino, F. Cinili, "Input-output decoupling control by measurement feedback in four wheel-steering-vehicles", IEEE Trans. Control Syst. Techno., vol. 17, 2009, pp. 1163-1172.

[17] J. Martinez, C. Canudas-de-Wit, "A safe longitudinal control for adaptive cruise control and stop-and-go scenarios", IEEE Trans. Control Syst. Techno., vol. 15, 2007, pp. 246-258

[18] M. Mboup, C. Join, M. Fliess, "Numerical differentiation with annihilators in noisy environment", Numer. Algor, vol. 50, 2009, pp. 439-467.

[19] S.A. Nobe, F-Y. Wang, "An overview of recent developments in automated lateral and longitudinal vehicle controls", IEEE Int. Conf. Syst. Man Cyber., Tucson, 2001.

[20] L. Nouvelière, Commandes robustes appliquées au contrôle assisté d'un véhicule à basse vitesse, Thèse, Univ. Versailles-Saint-Quentin, 2002.

[21] H. B. Pacejka, Tire and Vehicle Dynamics, Elsevier, 2005.

[22] M. Plochl, J. Edelmann, "Driver models in automobile dynamics application", Vehicle Syst. Dynamics, vol. 45, 2007, pp. 699-741.

[23] C. Poussot-Vassal, O. Sename, L. Dugard, P. Gaspar, Z. Szaboc, J. Bokor, "Attitude and handling improvements through gain-scheduled suspensions and brakes control", Control Engin. Practice, vol. 19, 2011, pp. 252-263.

[24] C. Poussot-Vassal, O. Sename, L. Dugard, P. Gaspar, S.M. Savaresic, "Vehicle dynamic stability improvements through gain-scheduled steering and braking control", Vehicle System Dynamics, to appear in 2011 .

[25] R. Rajamani, H-S. Tan, B-K. Law, W-B. Zhang, "Demonstration of integrated longitudinal and lateral control for the operation of automated vehicles in platoons", IEEE Transa. Control Syst. Techno. vol. 8, 2000, pp. 695-708.

[26] H. Sira-Ramírez, S. Agrawal, Differentially Flat Systems, Marcel Dekker, 2004

[27] S. Tsugawa, "Vision-based vehicles in Japan: Machine vision systems and driving control systems", IEEE Trans. Indust. Electron., vol. 41 1994, pp. 398-405.

[28] J. Villagra, B. d'Andréa-Novel, S. Choi, M. Fliess, H. Mounier, "Robust stop-and-go control strategy: an algebraic approach for nonlinear estimation and control", Int. J. Vehicle Auton. Syst., vol. 7, 2009, pp.270-291. (http://hal.archives-ouvertes.fr/inria-00419445/en/)

[29] J. Villagra, B. d'Andréa-Novel, M. Fliess, H. Mounier, "A diagnosisbased approach for tireroad forces and maximum friction estimation", Control Engin. Practice, vol. 19, 2011, pp. 174-184.

[30] S. Zheng, Ho Tang, Z. Han, Y. Zhang, "Controller design for vehicle stability enhancement", Control Engin. Practice, vol. 14, 2006, pp. 1413-1421. 